\title{
El juez y el historiador: consideraciones metodológicas*
}

\section{The Judge and the Historian: Methodological Remarks}

\author{
Michele Taruffo
}

Autor:

Michele Taruffo

Universidad de Pavía, Italia

Recibido: 25-2-2021

Aceptado: 10-3-2021

Citar como:

Taruffo, Michele, (2021). El juez y el historiador: consideraciones metodológicas Doxa. Cuadernos de Filosofía del Derecho, 44, pp. 13-39. https:// doi.org/10.14198/DOXA2021.44.01

Licencia:

Este trabajo se publica bajo una Licencia Creative Commons Atribución 4.0 Internacional.

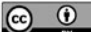

(C) Michele Taruffo

\begin{abstract}
Resumen
En este artículo el autor se plantea cuál es la naturaleza y la estructura del «juicio de hecho», que -en su opinión- no pueden ser establecidas a partir del estudio de las normas referidas a esa parte de la labor judicial, sino que requieren un estudio filosófico y metodológico. Por ello, parte de la comparación entre la tarea cognoscitiva del juez y la del historiador (recordando sus semejanzas y diferencias) $y$, asumiendo el paralelismo entre el «juicio de hecho" y la "explicación histórica», revisa las reconstrucciones de filósofos como Hume, Hempel o Carnap. Ello le lleva a proponer un modelo de juicio de hecho en el que las generalizaciones empíricas y máximas de experiencia cumplen una función semejante a las "leyes de cobertura» en el modelo nomológico-deductivo de la explicación científica, pero dándole al razonamiento del juez una naturaleza inductiva. No obstante, considera que este modelo es suficiente para aceptar que las Cortes Supremas pueden realizar una revisión de la corrección del juicio de hecho sin necesidad de un nuevo examen de la fiabilidad de los datos de los que parte.
\end{abstract}

Palabras clave: Juicio de hecho; explicación científica; explicación histórica; juez; historiador; inducción.

\begin{abstract}
In this article, the author brings up the question of what is the nature and structure of the "factual judgement", which -in his opinion- cannot be established from the study of the norms referring to that part of the judicial work, but the answer requires a philosophical and methodological study. For this reason, he begins with the comparison between the cognitive task of the judge and that of the historian (highlighting their similarities and
\end{abstract}

\footnotetext{
* Traducción de Maximiliano A. Aramburo C. Título original: Il giudice e lo storico: considerazioni metodologiche. Publicado por primera vez en la Rivista di Diritto Processuale, vol. XXII (II serie), 1967, pp. 439-465. Se trata de la primera publicación del autor, hasta ahora no traducida al español.
} 
differences) and, by assuming the parallelism between the "factual judgement» and the "historical explanation", he reviews the reconstructions of philosophers such as Hume, Hempel or Carnap. This leads him to propose a model of factual judgement in which the empirical generalisations and the maxims of experience fulfil a similar function to the "covering laws» in the nomological-deductive model of scientific explanation, but giving an inductive nature to the reasoning of the judge. However, he considers that this model is sufficient to accept that the Supreme Courts can carry out a review of the correctness of the factual judgement without the need for a new examination of the reliability of the data from which it arises.

Keywords: Factual judgement; scientific explanation; historical explanation; judge; historian; induction.

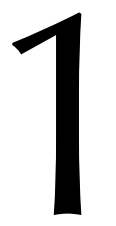

-. El principio de derecho procesal según el cual el juez debe fundamentar la decisión en su convencimiento racional, que se deriva del examen y valoración de los elementos que le permiten reconstruir la situación de hecho que subyace a la controversia, plantea el problema relativo al procedimiento cognoscitivo que ese juez debe afrontar, con el objeto de formular el llamado «juicio de hecho».

Tal juicio puede estudiarse según diversas perspectivas, no reconducibles a una simple exégesis de las normas que se refieren a esta parte de la labor judicial. Así, puede decirse que tales normas son necesariamente genéricas, porque el problema no se plantea tanto en términos identificables a través de la literalidad normativa, cuanto en términos filosóficos, lógicos o metodológicos, que presuponen una indagación llevada a cabo con instrumentos diferentes de los que el jurista suele usar. En otros términos, aunque las normas de derecho probatorio establecen los límites de legitimidad dentro de los cuales debe desarrollarse la investigación del juez en torno al hecho, para que se respeten los criterios de justicia procesal, no es posible extraer de ellas una definición de la naturaleza del juicio de hecho; ni, por otra parte, podría el legislador suministrarla sin violar el principio de libre convencimiento del juez.

Ese convencimiento es el producto de un procedimiento intelectual y racional tan complejo y variado, en relación con las situaciones particulares y concretas, que sin duda puede considerarse que es imposible su esquematización, que se resolvería además en un perjudicial endurecimiento de las fórmulas, necesariamente abstractas y generales, de la norma escrita.

No puede decirse tampoco que el problema del juicio de hecho es susceptible de resolverse en el análisis último de una serie de cuestiones relativas al procedimiento probatorio general, o a los medios de prueba en particular, dado que éstos tienen que ver con los medios predispuestos por el legislador para que el juez pueda identificar los datos de hecho útiles para la formulación del juicio, pero no tienen ninguna relevancia o utilidad para lo que tiene que ver con la naturaleza del juicio mismo. Incluso en el caso límite en el que de la práctica de los medios de prueba resultasen todos los elementos necesarios para la reconstrucción de la situación de hecho, de todas formas, 
correspondería a la valoración discrecional del juez el establecimiento de las relaciones entre tales elementos y la identificación de su grado de admisibilidad, para determinar su valor probatorio. Es en estos actos de juicio, más que en los procedimientos con los que se identifican los datos de hecho utilizables, que se lleva a cabo lo que verdaderamente puede denominarse juicio de hecho: si las pruebas suministran los elementos que hacen parte del juicio, su formulación tiene lugar cuando el juez madura su propio convencimiento en torno a ellos.

Aunque la investigación de carácter jurídico se revela de importancia secundaria, al menos en lo que tiene que ver con las normas de derecho probatorio, y en cierto sentido apenas accesoria con respecto al núcleo del problema - y debe tarde o temprano dejar campo a un estudio de tipo muy diferente-, sí hay un aspecto de la indagación para el cual la solución de un problema de naturaleza claramente jurídica está condicionada por la respuesta que se de a la cuestión del juicio de hecho desde el nivel de la indagación lógica. La atribución a la Corte de Casación de la potestad de examinar la lógica formal del razonamiento judicial comporta, en efecto, un juicio diferente acerca de la naturaleza del instituto de la Casación, según se atribuya más o menos, a tal razonamiento, y en particular al juicio de hecho, una estructura lógica objetiva y abstractamente verificable: en caso afirmativo, la Corte de Casación tendría evidentemente los caracteres que el legislador ha querido atribuirle, mientras que en el caso negativo sería necesario considerarla esencialmente, contra la ratio legis aparente, un juez de mérito en tercera instancia.

A este propósito, la norma no contiene indicaciones determinantes acerca de la naturaleza del juicio de hecho, y su carácter lógico objetivo se presupone implícitamente desde el momento en que se confiere a la Corte la facultad de controlarlo, aunque sea únicamente a través del examen de la motivación, desde un punto de vista meramente formal. En qué consista o deba consistir realmente ese carácter lógico, no es posible deducirlo del texto del art. 360 num. 5 del Codice di Procedura Civile. De otra parte, se puede repetir a este propósito la argumentación ya expuesta, pues no parece posible que el legislador formule prescripciones más precisas sobre el modo en el que el juez determina su propio convencimiento sobre los hechos. La naturaleza del juicio de hecho es, también desde este punto de vista, una cuestión a la que no puede darse ninguna respuesta satisfactoria, salvo que se quiera permanecer en el plano de la indagación propiamente jurídica, aunque debe reconocerse que se trata de un argumento de extrema importancia en el ámbito del derecho procesal.

Se ha dicho que el tema puede afrontarse, dejando entre paréntesis por los motivos brevemente reseñados el aspecto relativo al derecho positivo, desde diversos puntos de vista, según se quiera destacar una u otra de las diferentes caras del problema. Es posible, por ejemplo, adoptar una perspectiva eminentemente filosófica o, más propiamente, gnoseológica, si uno se propone analizar el acto mediante el cual el juez llega al conocimiento del hecho, a la luz de una determinada concepción de la relación entre sujeto 
cognoscente y objeto conocido ${ }^{1}$, para concluir que es de naturaleza intuitiva y excluir cualquier posibilidad de esquematización lógica, llegando al conocimiento pleno y cierto de lo que representa el objeto de investigación del juez.

Por otra parte, es posible asumir como objeto de análisis al juez individual, con su particular personalidad, y ver el problema en clave exclusivamente psicológica ${ }^{2}$, llegando a afirmar, en consecuencia, que la decisión se deriva de una serie de eventos físicos que se verifican siguiendo el esquema estímulo-reacción, que no es susceptible de representarse en leyes generales y constantes, de donde se concluye que el juicio de

1. Esta es, reducida a sus términos más simples, la perspectiva en la que se ubica, en coherencia con su concepción idealista de conocimiento como "presencia» inmediata del objeto ante el sujeto cognoscente, G. Calogero (La logica del gindice e il suo controllo in Cassazione, Padua, 1937; II ed., Padua, 1964). Sus soluciones, simples y evidentes desde una aproximación superficial, son ricas en determinantes implicaciones filosóficas y gnoseológicas, de las cuales sus muchos seguidores quizás no se han dado cuenta. Que la tesis de Calogero no sea aceptable — con independencia del acuerdo que haya sobre ciertos presupuestos filosóficos- se hace evidente en el hecho de que parece una derivación natural de la manera en la que él formula el procedimiento del conocimiento, lo cual se concluye sin duda alguna de un examen comprehensivo de su pensamiento. Si bien éste no carece de coherencia interna, algunas de sus conclusiones no pueden aceptarse sin aceptar implícitamente, con ello, los presupuestos metodológicos en los que se fundamenta. En el mejor de los casos, no es siquiera posible plantear formulaciones de este tipo por fuera de la gnoseología idealista, cuyo mejor instrumento es un acto de intuición genérica que, no obstante, el amplio predominio del idealismo en nuestra cultura filosófica, aún resulta misterioso e indefinible.

2. En esta dirección se ubican, con el objetivo de disolver el problema lógico del razonamiento judicial, las tesis que hacen pertenecen a la corriente de pensamiento del realismo jurídico americano. Aunque este es escasamente homogéneo y a menudo se corre el peligro de atribuir a toda la corriente opiniones que no son más que de un autor particular, no compartidas por otros, me parece que sobre el problema del juicio de hecho, las diferentes posiciones convergen en dos tesis principales, fácilmente conciliables entre sí: como todo acto cognoscitivo del juez es de naturaleza intuitiva (el llamado hunch) y no sigue un procedimiento lógico, tal actividad de conocimiento y juicio sólo puede ser analizada en sus componentes psicológicos, adoptando como objeto de la investigación la personalidad de cada juez en particular. El punto de llegada natural de una perspectiva como esta es la inevitable afirmación de la imposibilidad de conocer todos los procesos psíquicos en los que se lleva a cabo el juicio, pues tal actividad sigue siendo «inefable».

A partir del hecho de que por esta vía lo que se estudia ya no es el juicio, sino el juez, y de que la reducción de lo primero a la personalidad del segundo parece arriesgada y apriorística, se debe anotar que, aunque es absurdo negar la validez y utilidad de un estudio psicológico del comportamiento del juez (si bien los realistas terminan negando esta posibilidad), no es menos absurdo pretender que únicamente es legítima y está justificada la investigación de naturaleza psicológica sobre la decisión judicial y los motivos que la explican. No solo no es posible negar la validez de un examen lógico del juicio afirmando la utilidad de un estudio en clave psicológica: lo que es realmente equivocado en las tesis de los realistas es la pretensión de refutar los resultados de un examen metodológico del problema, a partir de observaciones llevadas a cabo en el nivel de la investigación psicológica (además de que se emplean nociones de psicología que son apenas suficientes para un tratamiento superficial del problema).

Sobre el juicio de hecho, véase, por ejemplo, Frank J., Law and the Modern Mind, Nueva York, 1949, especialmente las páginas 100-117; y del mismo autor, "What Courts do in Fact», 26 Illinois Law Review, 1932, p. 645; "Words and Music», 47 Columbia Law Rev., 1947, p. 1259; «Say it with Music», 61 Harvard Law Rev., 1948, p. 922.

Cfr. además, Paul J.: The Legal Realism of Jerome N. Frank, La Haya, 1959; Cohen M. y Nagel E.: An Introduction to Logic and Scientific Method, Nueva York, 1934, p. 157 y ss.; Hutcheson N., "The Judgement Intuitive: The Function of the Hunch in Judicial Decisions», 14 Cornell Law Quart., 1929, p. 274 y ss.; Cohen M., «The Place of Logic in the Law», 29 Harvard Law Rev., 1929, p. 622.

Doxa. Cuadernos de Filosofía del Derecho, (2021), 44, pp. 13-39 
hecho no es un juicio en la acepción común del término, sino el fruto de una experiencia emotiva del juez.

Es también posible, y la serie podría continuar, tomar en consideración el esquema formal del procedimiento de conocimiento y valoración que lleva a cabo el juez $z^{3}$, en el intento de elaborar el modelo lógico de tal procedimiento, en el que se identifica el razonamiento judicial, concebido como conjunto orgánico de lugares y relaciones lógicas constantes.

Uno de los modos de ocuparse de este tema es el que parte de la consideración del objeto de la actividad cognoscitiva del juez, para establecer, en relación con ella, cuál es el procedimiento racional que se lleva a cabo y dar una representación que tenga, si es posible, una admisibilidad intersubjetivamente válida.

Un análisis de este género inicia con destacar, poniendo con ello un punto de partida estable, que es tarea del juez reconstruir, sobre la base de un cierto número de datos de hecho que se pueden considerar conocidos por él, una situación concreta que se ha verificado con antelación y de la cual él no tiene y no puede tener ninguna experiencia directa. El juicio de hecho consistirá entonces en el vínculo lógico individualizado entre una serie de hechos conocidos de cierta manera y considerados relevantes, y un hecho o un suceso inicialmente desconocido (en su existencia real o en cuanto a algunos de sus caracteres o modalidades de ocurrencia), y en el juicio con el cual se formula la hipótesis cuya representación constituye.

Esta inicial y, dentro de ciertos límites, obvia afirmación en torno a la naturaleza del juicio de hecho, sugiere una asociación inmediata con lo que comúnmente se considera que es la obra del historiador, el cual parece estar, en relación con el objeto de su investigación, en la misma posición en la que se encuentra el juez cuando debe reconstruir el hecho. Tal similitud, a primera vista claramente evidente, parece constituir una hipótesis de trabajo válida, en el sentido en que se revelan útiles, con respecto al problema del que nos ocupamos, los resultados que se han obtenido en el campo de los

\footnotetext{
3. A esta tercera categoría de hipótesis pertenece la doctrina tradicional, dominante en la cultura jurídica alemana y en la italiana, que ve en el silogismo judicial el esquema lógico del razonamiento del juez.

Aunque esta parte de la justa exigencia, erróneamente repudiada por las doctrinas a las que se ha hecho referencia en las notas 1 y 2 , de aislar en el ámbito del procedimiento que lleva a la decisión una estructura formal bien definida y constante, no logra evitar algunas dificultades sustanciales de orden lógico y metodológico. Para limitarnos a citar algunas sin desarrollarlas en argumentos completos, baste recordar que: $a$ ) el silogismo judicial se amplía necesariamente en un sorites, del que no es posible establecer su origen lógico, y que hace ampliamente indeterminada la estructura del razonamiento; $b$ ) la premisa de derecho es normativa y no descriptiva, y no se ajusta por ello a las características formales del silogismo clásico; $c$ ) la validez del silogismo como instrumento de conocimiento está estrictamente condicionada por el acogimiento de los presupuestos ontológicos de la filosofía aristotélica, lo que relativiza su valor, historizándolo; $d$ ) en el juicio de hecho, la estructura deductiva reclama que se pueda recurrir en todos los casos a aserciones descriptivas de carácter universal, las cuales son utilizables sólo raramente, como se verá en el texto.

Para las más claras exposiciones de la tesis del silogismo judicial, cfr. Stein F. Das Private Wissen des Richters, Leipzig 1893; Wehli A.: «Beiträge zur Analyse der Urteilsfindung», en Festschrift für A. Wach, Leipzig, 1913; Rocco A., La sentenza civile, Torino, 1906, p. 5. y ss.; Calamandrei P., «La genesi lógica della sentenza civile», en Studi sul processo civile, vol. I., Padua 1930, p. 4. y ss.; Carnelutti F., «Limiti del rilievo dell'error in iudicando in Corte di Cassazione», en Studi di diritto processuale, vol. I, Padua, 1925, p. 384 y ss.
} 
estudios de metodología de la historiografía. Si la hipótesis es válida o no, más allá de una consideración tan superficial, solo lo podremos afirmar al concluir la investigación, pero puede decirse que tiene, al menos, el mérito de que hace posible comenzarla.

2 - La afinidad entre el método del historiador y la actividad de indagación que lleva a cabo el juez ha sido destacada por la mayor parte de nuestros procesalistas, al punto que se ha convertido casi en un lugar común considerar resuelto el problema del juicio de hecho, cuando se llega a decir que el juez se comporta como el historiador. Nuestra doctrina se ha inspirado sustancialmente, al aceptar esta tesis, en las formulaciones que de ella hicieron Calamandrei ${ }^{4}$ Calogero ${ }^{5}$ y que no parece que hayan tenido profundizaciones o revisiones críticas posteriores. Aunque no conviene intentar un listado de todos los autores que han adherido a estas concepciones, es suficiente en esta sede hacer un breve examen de su contenido más significativo.

Calamandrei considera que la similitud entre el método del juez y el del historiador se funda en una serie de razones, de las cuales las más relevantes son: el objeto de ambas investigaciones es del mismo tipo, constituido por el hecho pasado que debe ser reconstruido sobre la base de datos preexistentes a la indagación misma, y que suministran los elementos necesarios para esa reconstrucción; en ambos casos la investigación se desarrolla para garantizar en lo posible la imparcialidad y la objetividad del juicio; la formulación del juicio tiene en ambos casos la función de resolver cuestiones estructuralmente semejantes, a saber: el problema de la identificación del supuesto de hecho concreto para el juez, y de la llamada Frage para el historiador. Encuentra, además, una notable similitud entre el procedimiento que en el lenguaje jurídico toma el nombre de valoración del material probatorio y que en el lenguaje histórico-filosófico se suele llamar crítica de las fuentes. Con el objeto de delimitar el campo de validez de sus afirmaciones, Calamandrei subraya algunos aspectos de la actividad del juez, relacionados con los criterios generales de orden procesal a los que el juez debe subordinar el desarrollo de su indagación, y a los actos que caracterizan de modo específico la conducta que el juez debe seguir para llegar al conocimiento del hecho, diferenciándola del modo de proceder del historiador, más libre y elástico.

Estas características limitativas están representadas principalmente en la posición esencialmente pasiva del juez frente al tema de indagación, en el sentido de que sólo puede serle propuesto por las partes, y no puede ser elegido por el juez (cosa que, en cambio, hace habitualmente el historiador): esto vale incluso en la interpretación más restringida del criterio, que da lugar al llamado límite del petitum, en virtud del cual no solo el tema, sino también sus límites y sus características relevantes, están directamente determinadas por la voluntad de las partes. El juez concentra su indagación sobre los

4. Cfr. Calamandrei, «Il giudice e lo storico», finalmente aparecido en Studi sul processo civile, vol. V, Padua 1947, p. 27 y ss.; cfr. también Redenti E., Profili pratici del processo civile, Milán 1938, p. 444; Croce B., La storia come pensiero e come azione, Bari 1938, p. 278; Riduzione della filosofia del diritto alla filosofia dell'economia, Nápoles, 1926, p. 174.

5. Cfr. Calogero, La logica del giudice..., cit. p. 128 y ss. 
hechos alegados sin poder violar este límite, con la consecuencia adicional de que si un hecho se alega de manera concordante por ambas partes, debe ser considerado verdadero, con independencia de cualquier indagación al respecto, al tiempo que si un hecho no es alegado por ninguna de ellas, debe considerarse irrelevante e inexistente. Otras limitaciones tienen que ver con el modo de desarrollar la indagación, en el sentido en que mientras el historiador es completamente libre de elegir la vía que considere más conveniente para obtener un cierto resultado, el juez está obligado al uso de ciertos procedimientos típicos establecidos por las normas de derecho probatorio; además, la existencia de las llamadas pruebas legales reduce, a menudo de manera determinante, la libertad de convencimiento del juez, que de otra parte no puede abstenerse de decidir, mientras que el historiador es igualmente libre en la formulación de su propio juicio, para poder incluso decidir que no considera suficientemente justificada ninguna decisión. A pesar de estas dificultades, Calamandrei reafirma que la investigación del juez es siempre de tipo histórico, por el hecho fundamental de que también el historiador formula el juicio, de manera análoga al juez, haciendo uso de criterios de probabilidad y verosimilitud ${ }^{6}$.

Calogero se ubica en la misma línea de pensamiento, aunque se basa en presupuestos filosóficos particulares y justifica la afirmada analogía entre la posición del juez y la del historiador frente al hecho, con la consideración de que ambos tienen el mismo interés exclusivo en la acción del hombre, y no atribuyen ningún significado a un acontecimiento natural, salvo cuando es momento y fundamento de un acto humano.

Otro elemento de confirmación de la analogía, ya propuesto por Calamandrei, es que tanto el juez como el historiador tienen ante sí el hecho como algo que debe reconstruirse, no como una realidad existente, y por lo tanto la gnoseología del proceso de conocimiento resulta idéntica a la del proceso mental que sigue el historiador. La presencia de límites procesales a los que debe atenerse el juez, y que no están en la tarea del historiador, no basta para diferenciar de modo sustancial la indagación que ambos llevan a cabo en torno a los mismos fenómenos.

En línea de principio, pienso que puede llegarse a un acuerdo sobre la validez fundamental del tipo de ideas expuesto, dado que al nivel de profundidad en el que se ubican los núcleos de las tesis de Calamandrei y de Calogero, no se necesitan justificaciones adicionales: en efecto, esto se deriva de manera bastante obvia de la cercanía de las dos imágenes, relativas a la actividad del juez y del historiador, ya tradicionales y familiares, aunque no precisamente definidas.

Quisiera observar, sin embargo, que aunque la analogía en la que se fundan es difícilmente discutible, no puede considerarse como una solución satisfactoria para el problema del procedimiento de reconstrucción del hecho. Más que una respuesta original a tal problema, no parece ser más que una reformulación de la pregunta en términos más amplios, pues si no hay duda de que la tarea del juez es en cierta medida

6. Cfr. Calamandrei, «Verdad y verosimilitud en el proceso civil», en Rivista di diritto processuale, 1955, I, 164, y en Studi sul processo civile, vol. VI, Padua, 1957, p. 111. 
proporcional a la del historiador, esto no ofrece ninguna indicación acerca del procedimiento a través del cual se materializa la indagación, ni precisa las características de aquello que constituye el objeto de dicha indagación, ni aclara en qué consisten los datos en los que se funda. Además, si bien es cierto que se reconoce la necesidad de que el juicio de hecho sea racional y objetivo, no se indica ningún criterio con base en el cual puedan identificarse estas características en su real naturaleza. Análogamente, decir que el juez y el historiador afrontan los mismos problemas, no significa estudiar la manera en la que los afrontan, así como la asimilación entre el acto de valoración probatoria y el de la crítica de las fuentes, no resuelve la cuestión de la justificación racional de estos juicios.

En otros términos, la tesis que se ha expuesto constituye solo en apariencia una solución al problema del juicio de hecho, porque que en realidad no analiza la estructura lógica del procedimiento con el que llega a formularse, sino que indica genéricamente su objeto y algunas reglas negativas, sin suministrar una definición cualquiera en sentido positivo. Con esta tesis se obtiene únicamente el resultado de hacer necesaria, a propósito de la obra del historiador, la formulación de las cuestiones que se plantean a propósito del juez: pero el problema sigue abierto.

Un juicio sobre la tesis tradicional, entonces, se puede resumir en esta alternativa: o bien ésta, por plantearse en términos muy generales, no suministra ninguna respuesta al problema del juicio de hecho o bien, habiéndose formulado la relación con la metodología historiográfica, se abre la posibilidad de considerar válida para el juez toda respuesta que, sobre la base de los más variados y diversos presupuestos filosóficos, se haya dado o pueda darse sobre el objeto o sobre el método de la historia. Resulta evidente que en ninguno de los casos se logra obtener una clarificación suficiente, en el plano metodológico, si no se profundiza en el examen del proceso de conocimiento histórico. La validez de las formulaciones en cuestión, por tanto, está limitada al nivel de una intuición genérica, no respaldada por instrumentos adecuados de indagación.

3-. En el ámbito de un estudio dirigido a identificar el modelo lógico del juicio de tipo histórico y con el objeto de obtener elementos útiles para el análisis del juicio de hecho, me parece útil destacar el concepto de explicación del hecho. Explicar un hecho significa esencialmente llevar a cabo un acto escindible en dos momentos lógicos: aquél en el que se plantea una hipótesis sobre el modo en que ese hecho ha tenido lugar, y aquél en el que se aclaran las razones por las que se ha considerado conveniente adoptar esa hipótesis en lugar de otra, fundamentando la elección en datos de hecho establecidos y sobre un razonamiento que emplea esos hechos para obtener de ellos algún beneficio. Se puede decir que de esta manera el hecho está «explicado" porque se inserta en un contexto de carácter fáctico en el que se determinan las relaciones lógicas entre los elementos de hecho contenidos en él, y por lo tanto también el hecho en cuestión: el hecho se explica precisamente con base en sus relaciones con otros hechos conocidos.

Estudiar la estructura lógica de la explicación del hecho significa entonces aclarar la naturaleza de los elementos que la componen y el esquema según el cual esos 
elementos se disponen en sentido convergente hacia el hecho desconocido que se pretende reconstruir. Aunque stricto sensu la expresión «juicio de hecho» se aplica mejor a la sola enunciación de la hipótesis, no me parece equivocado considerarla sinónimo de «explicación", indicando con esta palabra todo lo que en ella se comprende, pese a que en el lenguaje común «explicación» significa a su vez únicamente la exposición de las razones por las que el juicio sobre un hecho se considera fundado. Dejando en la sombra los problemas que surgen alrededor de estas distinciones, para los cuales sería necesario un amplio análisis que no es posible aquí, conviene examinar el concepto lato de juicio de hecho, considerándolo semejante a la explicación de la hipótesis sobre el hecho o, de manera más simple, como explicación del hecho.

La problemática de la explicación del hecho en el campo de la filosofía de la historia ha sido desarrollada especialmente en el ámbito de la cultura anglosajona ${ }^{7}$, tanto porque en ella resultan menos vivas las sugerencias del pensamiento idealista ${ }^{8}$, que logra solo mínimamente superar el empirismo de la filosofía anglosajona, como por el desarrollo de los filones más fecundos de la filosofía inglesa, constituidos por el estudio del lenguaje llevado a cabo por los analíticos y por el estudio de la lógica que tiene su resultado quizás más importante en la obra de Bertrand Russell.

Aunque estas orientaciones descuidan la dimensión histórica de los problemas de los que se ocupan, sus instancias metodológicas son avanzadas y tienen tal precisión y eficacia que han sido acogidas incluso en el ámbito de la historiografía, en la que se identifican problemas lógicos y de método no menos graves que los que se plantean en el ámbito de las ciencias naturales.

Hume y los empiristas en general afirmaron que toda explicación (hay, por tanto, un intento de definir el modelo de la explicación) toma la forma de una correlación entre un evento, que constituye el explicandum, y otro evento o conjunto de eventos que constituyen la «causa» o la "condición» del primero. En otros términos, un evento está explicado cuando se hace referencia a otro evento de un tipo que, en el pasado, siempre se ha observado que acompaña el tipo de evento que debe ser explicado: es decir, se relaciona bajo una ley o generalización de la cual se convierte en un caso particular. Esta ley afirma una regularidad del tipo: siempre que se verifica un evento del tipo $C$,

7. Cfr. Rosi Pietro, «Teoria della storia e della metodologia storiografica nel pensiero inglese contemporáneo», en Riv. Storica italiana 1954, p. 68 y ss. Cfr. también, además de las obras que se citarán a continuación: Braithwaite R.B. Scientific Explanation, Cambridge 1953 y "Teleological Explanation", en Proceedings of the Aristotelian Society, 1946-7, p. II; Cornfortg K., «Explanation in History», en Proc. of the Atist. Soc., Suppl. Vol. 1935; Crawford R.M., «History as a Science», en Historical Studies, Australia y Nueva Zelanda 1947; Dray W., «Explanatory Narrative in History», en The Philosophical Quarterly 1954 y, del mismo, Laws and Explanation in History, Oxford 1957 y Philosophy of History, Englewood Cliffs 1964; Hospers J., "On Explanation», en Journal of Philosophy of Science, Englewood Cliffs 1963; Mandelbaum M., "Causal Analysis in History", en Journal of the History of Ideas, 1942 y The Problem of Historical Knowldege, Nueva York 1938; Strong E.W., "Criteria of Explanation in History", en Journal of Philosophy, 1952; Swabey M.C., The Judgement in History, Nueva York 1954; Teggart F.G., "Causation in Historical Events", en Journal of the History of Ideas, 1942, y Theory and Process of History, Berkeley y Los Angeles 1941; Trevelyan G.M., Clio, A Muse, Londres 1930.

8. Aunque en él se han inspirado algunos de los más importantes filósofos, como Bradley en Appearance and Reality, Londres 1893. Al respecto, cfr. Abbagnano, N., Il nuovo idealismo inglese ed americano, Nápoles, 1927. 
en ciertas condiciones de lugar y de tiempo, sucede un evento $E$, en condiciones de lugar y de tiempo en cierta forma vinculadas a las del evento $C$. Explicar un evento significaría entonces: 1) formular una ley o un conjunto de leyes de carácter universal; 2) afirmar la existencia de un conjunto de condiciones iniciales $a, b, c, \ldots n$, de manera que de 1) y de 2) se siga una tercera proposición que describe el evento en cuestión.

Esta manera de concebir la explicación, en sí misma bastante clara, ha dado lugar a una serie de graves ambigüedades por haber constituido el sustrato conceptual de todos los tipos concretos de explicación y ha sido reformulada en modos tan diversos que es casi imposible reconducirlos a su origen común.

La raíz de la ambigüedad, según Gardiner ${ }^{9}$, debe encontrarse en el hecho de que las diferentes definiciones del concepto de explicación construidas sobre la base de la misma idea de fondo, han sido elaboradas en niveles lingüísticos diferentes, con la consecuencia de que la definición propia de un tipo de lenguaje, como por ejemplo el científico, es diferente de la de otro tipo de lenguaje, como por ejemplo el que caracteriza el sentido común, y no son comparables. Considero que esta diferenciación de los tipos de explicación, entre sí y con respecto al modelo originario, que me parece bien identificada por Gardiner en el nivel del lenguaje, se debe al hecho de que, siendo el nexo de causalidad un punto esencial del modelo de Hume, sobre la definición de explicación se han reflejado todas las vicisitudes sufridas por el concepto de causa en la filosofía y, sobre todo, en la ciencia moderna, en el sentido que la explicación puede describirse en términos causales sólo en los casos, con los límites y en los modos en que el concepto de causa se acepta como válido ${ }^{10}$ : dado que esto no ocurre siempre, ni siempre de la misma manera, me parece que se confirma la tesis de Gardiner según la cual la definición de explicación es necesariamente relativa al contexto particular en el que se usa. Partiendo de este presupuesto, se examinará la explicación en el ámbito de la historiografía, sin pretender elaborar una definición de carácter general, válida para todas las ciencias.

En la concepción de Hume se inspiró Karl Popper ${ }^{11}$ al elaborar el esquema de explicación que ha recibido de Dray ${ }^{12}$ la denominación de "covering law model», cuya principal característica está dada por la presencia de una ley general que tiene la función de «cubrir» los casos particulares. Tal modelo — que según Popper es común también a la explicación científica, porque al tener estructura deductiva, unifica los conceptos de explicación, previsión y confirmación — ha recibido luego su más clara definición

9. Cfr. Gardiner, P., The Nature of Historical Explanation, Oxford 1952, pp. 5 y ss.

10. Sobre la relatividad histórica del concepto de causalidad como criterio de interpretación de la realidad, sobre las razones por las que se ha convertido en el canon del conocimiento científico y común, y sobre los límites esenciales de su validez gnoseológica, cfr. por ejemplo Bronowski J., The Common Sense in Science, Londres 1951.

11. Cfr. Popper, K., Logik der Forschung, 1935 y The Open Society and its Enemies, Londres 1945, p. 262.

12. Cfr. Dray, Laws and Explanation... cit. p. 1. La denominación más difundida de esta tesis es la del «regularity analysis» o «regularity interpretation». Cfr. Gardiner, op. cit., pp. 65, 70, 82. 
por obra de Hempel ${ }^{13}$, que mantiene intactos sus caracteres esenciales. Hempel afirma que la explicación de haberse verificado un evento de la específica forma $E$, en ciertas condiciones espacio-temporales, consiste en indicar sus causas o los factores determinantes de $E$. Afirmar entonces que un cierto conjunto de hechos de los tipos $A, B$, $\ldots N$, ha causado el evento a explicar, significa decir que, en relación con ciertas leyes generales, un conjunto de hechos de aquél tipo, está regularmente acompañado de un evento del tipo $E$. La explicación consiste entonces en: 1 ) un conjunto de proposiciones que afirman que se han verificado ciertos hechos $A, B, \ldots N$, en ciertas condiciones espacio-temporales; 2 ) un conjunto de hipótesis universales, de modo que: $a$ ) las proposiciones de ambos grupos resultan estar razonablemente confirmadas por evidencia empírica; $b$ ) la proposición que afirma que la verificación de $E$ puede deducirse de los dos grupos de enunciados.

A la fácil objeción de que un esquema de este tipo parece poco apto, quizás por su marcada formalización, para representar el iter lógico seguido por el historiador, Hempel responde que toda explicación propuesta como tal, o bien responde a los paradigmas de cientificidad así identificados, o bien, en cuanto no científica, es sólo una pseudoexplicación. Y aclara, contra la otra posible objeción según la cual el historiador no recurre a leyes universales, que el historiador en efecto no recurre a leyes universales, que a menudo la función teorética de tales leyes no se reconoce porque se usan de modo implícito, y que incluso el historiador, a diferencia del científico, encuentra generalmente a su disposición leyes formuladas de manera imprecisa, cuyos límites de extensión y validez están ampliamente indeterminados. Dado que en estos casos puede ser extremadamente difícil armonizar la ley con los datos de la experiencia empírica que resultan utilizables, el procedimiento resulta necesariamente poco riguroso y el mejor resultado posible no será entonces más que una pista para la explicación, a la que Hempel llama explanation skecth, que se aproxima al esquema formal de la explicación en la misma proporción en la que las regularidades o generalizaciones que el historiador usa como criterios de juicio, se aproximan a la forma de la ley científica.

Mientras autores como White ${ }^{14}$, Ducasse ${ }^{15}$ y Kaufmann ${ }^{16}$ se limitan a subrayar que la tesis de Hempel, bien fundamentada en lo esencial, necesita adaptarse en mayor medida a las características del procedimiento historiográfico, la misma tesis ha recibido críticas radicales de estudiosos de las formulaciones idealistas. Afirman la invalidez de extender al proceso de indagación histórica un modelo de explicación similar al que se

13. Cfr. Hempel C.G., "The Function of General Laws in History», en Readings in Philosophical Analysis, H. Feigl y W. Sellars, eds., Nueva York 1949, p. 459-471. Cfr. también: Hempel, «Philosophy of Natural Science», y Rudner R., «Philosophy of Social Sciences», ambos en Prentice Hall Foundation of Philosophy Series, Englewood Cliffs 1960; Brodbeck M., "Explanation, Prediction and Imperfect Knowledge», en Scientific Explanation, Space and Time, H. Feigl y G. Maxwell eds., Minnesota Studies in the Philosophy of Science, vol. III Minneapolis 1962, pp. 231-272.

14. Cfr. White M.G., «Historical Explanation», en Mind 1943, pp. 212-229.

15. Cfr. Ducasse C.J., «Explanation Mechanism and Teleology», aparecido también en Read. in Phil. Analysis, Feigl y Sellars eds., cit., p. 540.

16. Cfr. Kaufmann, F., The Metodology of the Social Science, Nueva York, 1944, p. 93. 
considera propio de las ciencias, basándose en el presupuesto común de que el objeto de la historia es diferente del objeto de las ciencias y exige, por lo tanto, un modelo de explicación original y autónomo.

Según Oakeshott ${ }^{17}$, el motivo fundamental que justifica el rechazo a la tesis de Hempel consiste en el hecho de que el historiador se encuentra frente a eventos únicos e irrepetibles, de lo cual se sigue la afirmación según la cual, si éstos se consideran ejemplos particulares de leyes generales, la historia no cumple su función, que es la de estudiar los hechos particulares tomados individualmente, y no las categorías conceptuales a las que esos hechos pueden reconducirse. Esta es, por el contrario, la tarea del científico, que estudia los eventos individuales con el fin de elaborar leyes de carácter universal, y que dirige a éstas, más que a los hechos particulares de los que se sirve, su propia atención. Mientras que Hempel subraya que las leyes generales se aplican a tipos de eventos, Oakeshott afirma que el historiador debe considerar el objeto de su examen como un hecho único, sin buscar clasificarlo como un evento de un cierto «tipo»: el ideal de la explicación no es la clasificación sino la identificación de un mundo de eventos intrínsecamente coligados entre sí, de modo tal que no haya ninguna laguna. El método del historiador no sería, por tanto, el de explicar por medio de generalizaciones, sino por medio de una completa precisión de los detalles del hecho bajo examen, resultante de la determinación de sus características individuales.

Entre las varias dificultades que enfrenta esta tesis, me limito a recordar las más relevantes: aunque los eventos históricos sean efectivamente únicos e irrepetibles, en el sentido de que dos hechos no se verifican nunca del mismo modo, esto no tiene relevancia alguna, porque lo mismo se puede decir de los hechos de los que se ocupa el científico, respecto de los cuales no se niega que a ellos puedan aplicarse leyes generales; de otra parte, aun admitiendo que los eventos históricos sean únicos en sí mismos, el problema es si pueden ser conocidos como tales.

Dado que el conocimiento de un hecho en su total y esencial unicidad es a duras penas concebible sólo en el caso en que se tenga de él experiencia directa, resulta incluso necesario recurrir, análogamente a lo que ocurre en el campo de la ciencia, a un modelo esencialmente clasificatorio de explicación.

Si se trata de un hecho pasado, todo lo que de él es posible tener es una cierta evidencia empírica que, para ser usada, postula el recurso a conocimientos o principios de carácter general. Además, el concepto de «continuidad» entre los eventos, sobre el que se basa esta concepción de la explicación, resulta confuso y equívoco, como lo es la idea de correlaciones «naturales» entre los hechos. Aunque estas observaciones no muestran la validez del modelo hempeliano, son suficientes para considerar inaceptable el propuesto por Oakeshott.

17. Cfr. Oakeshott N., Experience and its Modes, Cambridge 1952, p. 154.

Doxa. Cuadernos de Filosofía del Derecho, (2021), 44, pp. 13-39 
Otro intento por resolver el problema sobre la base de presupuestos idealistas ha sido desarrollado por Collingwood ${ }^{18}$, quien sigue la perspectiva en virtud de la cual el objeto del conocimiento histórico serían exclusivamente las acciones humanas, determinadas libremente, al menos dentro de ciertos límites, mediante elecciones y decisiones. El aspecto más interesante de esta tesis es que los hechos históricos no se consideran como meros eventos, sino como entidades poseedoras de un "contenido de pensamiento»: la explicación deberá consistir en la identificación del pensamiento del agente, de cuya acción - que es consecuencia directa de la decisión que la determina - representa la expresión. El historiador deberá entonces, para entender las razones de una acción y luego explicarla, «investigar» en su propia mente el pensamiento del agente, al menos en la medida en que éste haya producido la acción que constituye el hecho a explicar. La explicación, así, sería racional porque haría explícitos los motivos racionales de la acción, como la acción misma lo hace evidente. Aun dejando de lado el hecho de que semejante noción de racionalidad es bastante equívoca y discutible, se puede de todas formas observar que el alcance de la tesis de Collingwood es extremamente limitado, en el sentido de que podría ser válida solamente para el restringido grupo de casos que, en el complejo actuar humano, se fundan en una decisión racional, y dejaría de lado los que no son reconducibles a un origen similar.

Parece evidente que Collingwood considera racional, en el sentido que se ha dicho, toda acción humana; pero de este modo el concepto de racionalidad llega a disolverse completamente. Además, hay hechos que, aun siendo relevantes para la explicación de un comportamiento, no son a su vez explicables sobre la base de ese mismo concepto, pero mantienen interés, al menos indirecto, para el historiador: piénsese, por ejemplo, en eventos naturales o en cierto tipo de circunstancias ambientales.

De esta manera se controvierte la validez de la tesis de Collingwood, porque se funda en un presupuesto evidentemente inaceptable, como el de la general racionalidad $\mathrm{y}$ «humanidad» de todos los hechos que interesan al historiador. No solo resulta que éste puede explicar con la reconstrucción del pensamiento del agente sólo una parte exigua de los hechos, sino que además es dudoso que esa reconstrucción sea posible en un nivel útil de profundidad, incluso en el restringido campo de los hechos reconducibles al comportamiento humano.

Hempel ${ }^{19}$ añade que, aun si se admitiese que el historiador puede comportarse de la manera descrita, la definición "empática» de explicación estaría de todas maneras viciada de manera grave, al punto de no poder explicar el hecho. En efecto, en cualquier modo que se haya llevado a cabo la indagación, cuando el historiador expone su resultado, parece tener la forma de un enunciado que conecta de manera necesaria el hecho que el agente haya pensado en un cierto modo y el hecho de que haya llevado a cabo una cierta

18. Cfr. Collingwood R.G., The Idea of History, Oxford, 1946; y tambi' ne Dray, «Historical Understanding as Re-thinking», en Univ. of Toronto Quarterly, XXVII, n. 2, 1958, pp. 200-215.

19. Cfr. Hempel, The Function of General Laws..., cit., p. 352; y «Reasons and Covering Laws in Historical Explanation», en Philosophy and History, S. Hook ed., Nueva York, 1963, p. 155. 
acción: esto implica, por lo menos, una referencia a una ley psicológica y la explicación es insuficiente en le medida en que esta ley no está identificada y reconocida como tal.

Además, aun en los casos en que es posible reconstruir el pensamiento del agente, sería necesario recurrir a la ulterior asunción de un principio de carácter general, relativo a la racionalidad del agente mismo, que permitiese afirmar que, subsistiendo determinadas condiciones, él ha realizado aquella acción con certeza o al menos muy probablemente. De este modo, sin embargo, se vuelve nuevamente al esquema de la "covering law».

De las observaciones expuestas parece que resulta con suficiente evidencia la inaceptabilidad de las soluciones idealistas, de las cuales las dos tesis expuestas constituyen ejemplos significativos: responden por la vía de una primera aproximación a exigencias que parecen descuidadas por la estructura rigurosamente formal del modelo hempeliano, pero, recurriendo a instrumentos de conocimiento esencialmente intuitivos, no responden al objetivo de delinear con precisión satisfactoria el esquema de la explicación.

Aunque el esquema neopositivista sale casi indemne de los ataques que parte de los idealistas le han dirigido, se siente la necesidad, advertida incluso por el mismo Hempel al proponer la tesis de la «sketch explanation», de atenuar de alguna manera su carácter abstracto y su deductivismo mecánico, sin abandonar el objetivo de determinar con rigor metodológico el modelo de la explicación. El elemento del modelo hempeliano que incluso desde una consideración superficial resulta menos convincente es, sin duda, la presencia de leyes generales entre las premisas necesarias del razonamiento explicativo.

Diversos intentos, como los de Walsh ${ }^{20}$, Scriven ${ }^{21}$ y Rescher ${ }^{22}$, han sido llevados a cabo con el objetivo de limitar el alcance de las afirmaciones de Hempel en torno a la función de los principios universales en el mecanismo lógico de la explicación, sin transformar sustancialmente la naturaleza del modelo que él propuso. Los autores citados concuerdan, en esencia, en afirmar que las leyes a las que recurre el historiador en la elaboración de la explicación no tienen carácter de absoluta universalidad o generalidad, sino que son simples "generalizaciones» de validez semántica, restringida a limitadas y particulares dimensiones espacio-temporales y que, al no estar formuladas en términos de auténtica generalidad, dan lugar a un procedimiento solo aproximativamente deductivo. Aunque tales hipótesis se plantean en una justa dirección crítica con respecto al esquema original neopositivista, no me parece que ofrezcan una solución definitivamente satisfactoria del problema: si bien la imagen de la deducción en cierto

20. Cfr. Walsh W.H., An Introduction to Philosophy of History, Londres, 1951, cap. III.

21. Cfr. Scriven M., "Truism as the Ground for Historical Explanations», en Theories of History, Gardiner ed., p. 464, y, del mismo autor, «New Issues in the Logic of Explanation», en Philosophy and History, Hook ed., p. 339 y ss., $y$ «The Historical Explanation of Actiones Reconsidered», en el mismo volumen.

22. Cfr. Rescher N. y Helmer O., "On the Epistemology of the Inexact Sciences», en Management Science, VI, n. 1, 1959, pp. 25-40, y Rescher N. y Joynt C.B., "On Explanation in History», en Mind, LXVIII, 271, 1959, p. 383. Cfr. también: Donagan, A., "Explanation in History», reimpreso en Theories of History, Gardiner, ed., cit., p. 428. 
modo aproximativa responde bastante bien a las exigencias antes mencionadas, no se pude negar que ha tenido una formulación errada.

En efecto, si se excluye la posibilidad de recurrir a leyes de carácter universal, es necesario también excluir que el procedimiento en cuestión tenga naturaleza deductiva, dado que faltaría la condición más importante para la existencia del razonamiento deductivo, y no se puede considerar alternativa válida la de suponer una deducción vaga e imprecisa. Cuando se afirma que el historiador puede tener a su disposición solo uniformidades no generalizadas, formuladas en el nivel del sentido común, se llega a concluir que se trata de premisas de un razonamiento de tipo inductivo, que desemboca en un juicio de hecho que tiene todas las características de un juicio de probabilidad. No sería en este caso la inducción generalizadora elaborada por la lógica clásica, sino el procedimiento lógico mediante el cual se lleva a cabo el paso de una proposición particular a otra proposición particular, atribuyéndole a la segunda un determinado grado de confirmación lógica, sobre la base de la primera. Los conocimientos que usa el historiador, extraídos del sentido común, se expresan en proposiciones cuyo contenido se refiere a un número quizás indeterminado, pero en cualquier caso finito, de eventos conocidos: la impresión errada de su universalidad puede derivarse precisamente del hecho de que, en general, no está determinado de manera cuantitativa el conjunto de hechos a los que se refiere. En él no se encuentran conocimientos que se refieran a un genus de objetos o de eventos, de los que se predique una característica de la que gozan todos sus miembros, sino la afirmación de un predicado relativo a un cierto número de eventos, de los cuales se ha tenido cierta experiencia empírica.

Está claro que de esta manera el modelo hempeliano se modifica radicalmente, en el sentido en que, si se tiene en cuenta un cierto nivel de indeterminación de las proposiciones que constituyen las premisas generales, no es suficiente reducir la explicación a una «skecth explanation», sino que es necesario configurarla según un esquema de este tipo: $a$ ) aserciones relativas al hecho de que en un cierto número de casos, el evento $A$ se ha verificado de cierta manera, coligado al evento $B ; b$ ) aserciones relativas a la verificación, en el caso concreto, de un evento semejante a $B ; c$ ) conclusión consistente en la afirmación de que hay suficientes razones para considerar que probablemente también en el caso en cuestión, la presencia de $B$ es indicio o signo de que ha tenido lugar $A$.

4-. El valor de probabilidad de la conclusión, que de ninguna manera puede considerarse cierta, se debe al hecho de que la no generalidad de las premisas señaladas en a) admite siempre la posibilidad de que las cosas hayan ocurrido en realidad de manera diferente de como resultan descritas en la conclusión, la cual se funda sobre una masa de conocimientos empíricos tal, que no agota todos los casos posibles. La conclusión resulta entonces no como una representación cierta de lo que constituye el hecho a explicar, sino como una hipótesis formulada en torno a él, sobre la base de una cierta cantidad de datos utilizables, a los que estos mismos datos, que aparecen en $a$ ) y en $b$ ), permiten atribuir un cierto grado de confirmación lógica. Explicar el hecho significa entonces no tanto identificar vínculos causales entre el hecho en cuestión y otros hechos 
que puedan aparecer como condiciones o causas suyas, cuanto exponer las razones lógicas, fundándolas sobre un cierto conjunto de datos empíricos, por las que se decide considerar fundada, y elegir como válida, una cierta representación hipotética del hecho, que parece ser su más probable reconstrucción. Mientras que los autores antes citados entendían por explicación la descripción del modo en el que el evento a explicar fue causalmente producido por otros eventos, motivando de esta manera su existencia en el plano de la realidad de las cosas, si se adopta el esquema propuesto, explicar el hecho significaría exponer las razones por las cuales quien lleva a cabo la indagación considera justificado acoger como verdadera, con relación a los datos disponibles, una cierta hipótesis de tales datos, confirmada en un determinado nivel de probabilidad.

No se trata entonces de ubicarse en el plano de la realidad, sino en el del conocimiento: un juicio de conocimiento empírico está siempre formulado de manera inductiva y tiene inevitablemente la forma de la hipótesis probable: explicar el hecho significa explicar por qué una hipótesis es tan probable que puede ser elegida como verdadera a partir de los datos en los que se funda.

Una consecuencia adicional de lo que se ha dicho es que en el modelo de la explicación no se encuentran ya dos tipos diferentes de premisas, leyes generales y condiciones particulares, sino premisas cuyo peso es únicamente diverso desde el punto de vista cuantitativo. Los conocimientos útiles traídos del sentido común o de la experiencia son datos de observación empírica, del mismo modo en que lo son las afirmaciones en torno a hechos particulares formuladas a propósito del caso concreto: las primeras se diferencian de las segundas solo porque son relativas a un número más amplio de objetos, pero resultan del mismo procedimiento de experiencia empírica. La hipótesis que constituye la conclusión del razonamiento, y que representa el juicio sobre el hecho, se rige por una ciert evidencia empírica de la que es su única premisa lógica, y que comprende todos los datos que quien formula la hipótesis toma en consideración. Poniendo en relación lógica los dos elementos, hipótesis y evidencia empírica, se determina el grado de probabilidad que corresponde a la hipótesis y justifica su elección. Nótese, entonces, que mientras en el modelo hempeliano nos referíamos principalmente a «tipos» de eventos, a los cuales se hacían reconducir los eventos singulares para llevar a cabo la deducción, en el modelo inductivo aparecen solo eventos particulares, eventualmente vinculados únicamente, por motivos de comodidad práctica y no de necesidad teorética, por nexos de similitud que permiten sintetizar un número de experiencias concretas en un número mas restringido de aserciones. Pero por esa razón, esas aserciones no revisten carácter general y conservan su referencia semántica originaria a un grupo cuantitativamente finito de experiencias particulares.

Es necesario ahora aclarar las características de los conceptos principales que se usan para proponer el modelo inductivo de la explicación. Por hipótesis empírica no se entiende la asunción de un postulado tomado como verdadero por fuera de toda demostración, como ocurre con las hipótesis matemáticas o científicas, sino una proposición en la que se expresa un juicio relativo a la existencia o a las modalidades de un cierto hecho del cual, no obstante, no se tiene o no se puede tener conocimiento 
cierto y unívoco; juicio que se formula sobre la base de un conjunto de conocimientos empíricos, relativo a hechos diferentes de aquellos sobre los que versa el juicio. Se dice que éste constituye una hipótesis porque expresa una aserción fáctica no verdadera en sí misma, o analíticamente, sino que solo puede ser bajo ciertas condiciones, sintéticamente verdadera. Se trata de una hipótesis porque la verdad de la proposición depende de manera necesaria de ciertos elementos de confirmación y porque, cuando ésta se afirma, nunca se tiene la certeza absoluta de que la aserción hipotética responde a la realidad de los hechos, sino que se tiene solo un cierto grado de probabilidad sobre su verdad sintética.

La hipótesis es empírica porque, en la medida en que se formula sobre la base de conocimientos empíricos, son estos mismos conocimientos los que le atribuyen un cierto grado de confirmación: aun estando lógicamente confirmada, no se puede decir que sea una hipótesis puramente lógica. Hipótesis empírica no significa en este caso aserción que debe ser empíricamente verificada (como ocurre con las proposiciones científicas), sino que está formulada sobre la base de datos empíricos y confirmada únicamente por ellos. Una aserción de este tipo no es verdadera por que esté verificada, sino que es probablemente verdadera, en cuanto esté confirmada empíricamente. A diferencia de las hipótesis empíricas formuladas por el científico, que tienden a transformarse en tesis mediante la verificación, las formuladas por el historiador están destinadas a seguir siendo tales, aunque se pueda aumentar o modificar la amplitud y la estructura de la evidencia empírica sobre la que se fundan: la confirmación inductiva es su única justificación. Si el concepto de inducción remite inmediatamente al de probabilidad, genéricamente entendido, el de confirmación empírica inductiva remite al concepto particular de probabilidad lógica ${ }^{23}$.

Carnap define el concepto de probabilidad lógica como el grado de confirmación de una hipótesis «h» con respecto al enunciado de evidencia «e» relativo a los datos producidos por la observación, lo que lo distingue del de probabilidad como frecuencia relativa, que es la relación entre el número de veces en las que se verifica un cierto evento y el número de veces en que se verifica otro evento ${ }^{24}$. Se aproxima a las tesis

23. Sobre estos puntos son muy claras las observaciones de Carnap en Logical Foundations of Probaility (Londres, Chicago, 1950), p. 2.

24. Cfr. Carnap, Logical Foundations, cit., pp. 23 y ss. Dado que él concibe la teoría de la probabilidad como explicación de los conceptos precientíficos de probabilidad, identifica en dos conceptos recordados en el texto los explicanda de los que las varias teorías constituyen los explicata. Estos, según la distinción efectuada por E. Nagel («Principles of the Theory of Probability», en International Encyclopaedia of Unified Science, Chicago, 939, vol. I, n. 6, pp. 4 y ss.) se diferencian en tres categorías, que corresponden a las principales definiciones del concepto: a) la concepción clásica, formulada por J. Bernoulli y desarrollada por Laplace, para quien la probabilidad está definida como la relación entre el número de casos favorables y el de todos los casos posibles; $b$ ) la concepción de la probabilidad como objetiva relación lógica entre proposiciones, representada especialmente por J.M. Keynes y H. Jeffreys; $c$ ) la concepción de la probabilidad como frecuencia relativa, desarrollada principalmente por R. von Mises, H. Reinchenbach y por los modernos estudiosos de la estadística. 
de Keynes ${ }^{25}$ y de Jeffreys ${ }^{26}$ en que conciben la probabilidad como una relación lógica objetiva entre proposiciones, que en este caso se representan por la aserción hipotética «h» y por los enunciados que expresan los datos de la experiencia que constituyen «e»: la relación lógica instituida ente estos dos tipos de proposiciones produce el grado de confirmación lógica «c», de «h» respecto de «e». Los dos argumentes «h» $\mathrm{y}$ «e» se refieren a eventos, situaciones, entre otros, y se expresan en proposiciones que, puestas en relación de hipótesis a confirmación, dan lugar a una aserción de probabilidad lógica de un argumento con respecto a otro, aserción que en sí misma es analítica, es decir, lógicamente verdadera o falsa, y por lo tanto no fáctica. Una aserción de este género se deriva solo de un análisis lógico o semántico de los argumentos y es independiente de la contingencia de los hechos, aunque los argumentos se refieran a hechos. Se trata de un concepto lógico de probabilidad porque, al enunciar la hipótesis en «h» y la evidencia empírica en utilizable en «e», el problema de si está confirmada «h» por «e», y cuánto, se resuelve solo mediante un análisis meramente lógico de «e», «h» y de las relaciones entre sí. Esto no es un problema de hecho en el sentido en que para resolverlo sean necesarios conocimientos de hecho diferentes de los que se expresan en «e»: «e» $\mathrm{y}$ «h» se refieren a hechos, pero, una vez formulados, se trata solo de llegar a establecer entre ellos ciertas relaciones basadas en la identificación de su significado. Se puede decir que la relación entre «e» $\mathrm{y}$ «h», además de lógica, es de naturaleza semántica: se tendrá entonces un concepto semántico de confirmación. En otros términos, el valor de probabilidad lógica que de esa manera se atribuye a "h» (es decir: su grado de confirmación con respecto a «e») representa la medida del fundamento probatorio de la hipótesis. Decir, por ejemplo, que la probabilidad de «h» sobre «e» es alta, significa que «e» suministra un amplio fundamento a la asunción de «h», o bien, en términos de aplicación a una situación cognoscitiva, que si un observador X conoce «e», por ejemplo por observación directa, y nada más, tiene buenas razones para esperar que los hechos descritos en «h» hayan realmente ocurrido.

Evidentemente es posible, dada una cierta masa de datos de experiencia utilizables, formular diversas «h» en relación con ellos, relativas a un mismo hecho, en el sentido de que este puede reconstruirse de maneras diversas, aun en relación con el mismo conjunto de conocimientos iniciales, dado que estos pueden ser objeto de diferentes valoraciones. Se tendrá entonces la misma «e» en diferentes relaciones de probabilidad lógica, con una pluralidad de "h» de las cuales una debe ser asumida como aserción verdadera en torno al hecho, con preferencia sobre las demás.

La elección de la hipótesis a asumir como representación del hecho consistirá entonces en la determinación de la «h» que tiene el más alto grado de confirmación en relación con «e», es decir, en la asunción del juicio de hecho más admisible, sobre la

25. Cfr. Keynes J.M., A Treatise on Probability, Londres y Nueva York, 1921.

26. Cfr. Jeffreys H., Scientific inference, Cambridge 1931; «The Problem of Inference», en Mind 45 (1936), p. 324; Theory of Probability, Oxford 1939. 
base de los elementos dirigidos a justificarlo ${ }^{27}$. El contraste entre los diferentes grados de confirmación de una misma hipótesis, con la finalidad de establecer cuál de ellos es más elevado, implica resolver un problema metodológico que se me consentirá en esta sede dar por resuelto, por razones de brevedad.

Ese problema tiene que ver con la posibilidad de establecer una cuantificación, absoluta o al menos relativa, del grado de confirmación, antes presentada como una relación puramente lógica, y el método para conseguirla. Más precisamente, si es alcanzable la configuración de un vínculo lógico-semántico entre proposiciones, tal que la admisibilidad de una dependa del significado y de la forma lógica de las demás, es menos evidente la posibilidad de distinguir diferentes niveles de confirmación según un criterio cuantitativo. Si esto es claramente posible cuando se formulan diversas «h", cada una de las cuales se basa en una particular «e» de diferente amplitud respecto de aquella de las «e» en las que se fundamentan respectivamente las demás «h», más complejo es el problema que se tiene cuando diversas «h» se refieren a la misma «e». $\mathrm{Al}$ no poder desarrollar aquí todo el procedimiento seguido por Carnap ${ }^{28}$, me limitaré a anotar que, partiendo de la idea de que el grado de confirmación es la medida del fundamento probatorio de la hipótesis, es posible concluir que el valor numérico de la relación de probabilidad lógica entre la hipótesis y la evidencia, puede interpretarse como la estimación de la frecuencia relativa de verdad entre un cierto número de hipótesis igualmente probables, lo que permite establecer de esta manera el vínculo entre el concepto de probabilidad lógica, meramente formal, y el concepto de probabilidad como frecuencia relativa, esencialmente cuantitativo. Entonces es posible concluir que la regla para la elección racional entre varias hipótesis diferentemente confirmadas por una misma evidencia, se resuelve en el criterio por el cual debe considerarse como reconstrucción admisible del hecho (es decir, verdadera en relación con «e») la que se exprese en una proposición que tenga el más alto grado de confirmación inductiva con respecto a los datos empíricos utilizables.

5-. La profundización de algunos aspectos problemáticos de la metodología de la historia, aun limitándose a unos cuantos rasgos de carácter muy general y dejando de lado una serie de interesantes cuestiones (como la que tiene que ver con la relación entre juicios de valor y la objetividad histórica), ha permitido al menos bosquejar brevemente el esquema de lo que considero que es el real procedimiento lógico que el historiador

27. Sobre el concepto de grado de confirmación sobre la base de evidencia empírica, cfr., además de la citada obra de Carnap, Lenz J.W., "Carnap on Defining 'Degree of Conirmation'» en Philosophy of Science, 1956, p. 230 y ss.; Nagel E., Principles, cit., pp. 60 y ss.; Goodman N., «On Infirmities of Confirmation Theory», en Phil. Phen. Res., 8 (1947-8)., p. 149; Helmer O. y Oppenheim P., «A Syntactical Definition of Probability and of Degree of Confirmation», en Journal of Symbolic Logic, 10 (1945), p. 25; Hempel, «A Purely Syntactical Definition of Confirmation», en Journ. of Symb. Log., 8 (1943), p- 122 y «Studies in the Logic of Confirmation», en Mind, 54 (1945), pp. 1-121; Hempel y Oppenheim, «A Definition of 'Degree of Confirmation'», en Phil. of Sc., 12 (1945), p. 98; White M., "Probability and Confirmation», en Journal of Philosophy, 36 (1939), p. 323.

28. Cfr. Carnap, Logical Foundations, cit. pp. 163 y ss. 
sigue para llegar a formular el juicio de hecho. Éste se configura, entonces, como una hipótesis fáctica (es decir, que describe el hecho) en cierta proposición confirmada (con respecto a su admisibilidad) por la masa de conocimientos empíricos utilizables respecto al caso concreto, mediante el análisis de la relación lógico-semántica que se establece entre las proposiciones que expresan tales conocimientos y la aserción en torno al hecho que debe ser reconocido.

Se trata ahora de ver si el modelo lógico elaborado para representar las características formales de la investigación histórica puede ser también considerado una imagen del modo en que el juez forma su propio convencimiento, valorando y operando lógicamente sobre conocimientos de hecho que le son suministrados por la experiencia directa o por los resultados del procedimiento probatorio. Quedan fuera de los límites del examen los problemas relacionados con el modo en el que se descubren esos datos, y se considerará únicamente el momento en el que el juez establece su admisibilidad, elaborando a partir de ellos la reconstrucción del hecho.

La doctrina tradicional, sobre la base del planteamiento de Stein ${ }^{29}$ y, en general, el que los estudiosos alemanes le han dado al problema, afirma que los elementos de hecho, sean indicios o el resultado de la práctica probatoria, se valoran por el juez mediante el recurso a las llamadas máximas de la experiencia, concebidas como reglas o leyes generales que el juez formula con base en su propia experiencia o recibe del patrimonio de conocimientos del sentido común. Con base en la afirmada generalidad de dichas máximas, se elabora luego, en coherencia con la teoría del silogismo judicial, un modelo deductivo del juicio de hecho, en el que ellas fungen como premisas generales y los datos concretos como premisas particulares, concluyendo así que el juicio sobre el hecho resulta de la subsunción de las segundas en las primeras, siguiendo un procedimiento silogístico. Aunque no se llega al mismo nivel de profundidad lógica, este esquema es evidentemente análogo, en sus aspectos metodológicos, al esquema hempeliano, aunque los correspondientes orígenes culturales y teoréticos sean completamente diferentes. Se diría incluso que el segundo puede ser visto, con razón, como una reformulación más moderna y lógicamente más precisa, del primero, al menos desde el punto de vista estrictamente formal. Esta analogía sustancial ya es un elemento que acredita notoriamente la aplicabilidad de los esquemas elaborados en el plano de la metodología historiográfica al campo de las indagaciones judiciales sobre el hecho. En particular, se pueden formular en contra de las máximas de la experiencia, entendidas como generalizaciones extraídas del sentido común, las observaciones críticas que se han aceptado como válidas contra las supuestas leyes "cuasi» generales de las que haría uso el historiador. Las máximas se reducirían, entonces, a ser poco más que una masa de conocimientos particulares, que no están dirigidas de ninguna manera a fundamentar un procedimiento lógico deductivo.

Tal como el historiador, el juez sólo raramente puede remitirse a leyes verdaderamente generales, usualmente suministradas por la ciencia, y debe en cambio,

29. Cfr. Stein, Das Private Wissen..., cit. 
habitualmente, usar como criterios de juicio y de valoración de los elementos de hecho, conocimientos que no tienen valor lógico y semántico más amplio que los que resultan de la experiencia empírica de un cierto conjunto de casos particulares. Se puede entonces decir que para pasar de los datos de hecho empíricos utilizables, al juicio sobre el hecho propiamente dicho, el juez debe formular, en torno al hecho a reconstruir, una hipótesis que, si bien no puede ser demostrada deductivamente, está sometida a una posible confirmación lógica, en la medida en que así se desprenda del sistema de las relaciones lógicas entre «e» $\mathrm{y}$ «h». También el juicio de hecho es una hipótesis empírica del tipo «h», que llega a confirmarse en un cierto grado, por un conjunto de conocimientos empíricos del tipo «e», en el que hay tanto hechos percibidos directamente por el juez, como hechos determinados por él mediante la práctica de las pruebas, así como la masa de conocimientos empíricos que él utiliza, extraídos de su propia experiencia o del sentido común. Esa hipótesis, en cuanto es meramente inductiva y está empíricamente fundamentada, no puede suministrar de ninguna manera un conocimiento cierto y unívoco del hecho, sino apenas una representación verosímil que el juez, con su indagación lógica y concreta, debe llevar al máximo posible de admisibilidad objetiva. Se podrá decir que el conocimiento al que se atribuye el nombre de máximas de la experiencia es un instrumento de confirmación particularmente válido, en cuanto comprende aserciones relativas, a veces, a un amplio número de eventos y, por tanto, de vasto alcance semántico, pero esto sigue perteneciendo, perfectamente, del modelo de juicio de hecho inductivo y lógicamente probable.

Cuanto se ha dicho puede considerarse fácilmente como un ejemplo particular de la afirmación general, aquí aceptada en el plano metodológico, en virtud de la cual la simple experiencia empírica, si se queda en un nivel precientífico de conocimiento de los fenómenos, no permite formular afirmaciones o leyes de carácter general y universal en torno a dichos fenómenos, como se requieren para constituir las premisas de un razonamiento rigurosamente deductivo y que solo la ciencia, y con frecuencia ni siquiera ella, está en capacidad de suministrar.

De una afirmación de principio semejante, que no puede ser discutida en esta sede, pero que constituye de todas formas el presupuesto de la indagación metodológica que se ha llevado a cabo, desciende la consecuencia obvia de que todos los juicios en torno a hechos empíricos, en la medida en que se basan en conocimiento resultante de la experiencia común, tienen una estructura lógica de naturaleza inductiva y llegan a conclusiones no ciertas, sino apenas probablemente verdaderas.

Con base en lo dicho debe aclararse el sentido de los atributos de «racionalidad»y de «objetividad», aunque a menudo — y de manera confusa y no motivada — la mayor parte de la doctrina ha considerado como características reales o al menos como cánones deontológicos del razonamiento judicial.

Resulta evidente que la racionalidad es una característica intrínseca del procedimiento que se ha delineado, a partir de la simple observación de que en él no hay ningún momento o acto lógicamente necesario que pueda definirse como no racional. El elemento que en lógica constituye la única y verdadera antítesis de la racionalidad, 
que es la intuición, queda rigurosamente excluido y a ese respecto no es necesaria demostración alguna, en un procedimiento propiamente inductivo. Bastaría entonces subrayar que el esquema "grado de confirmación $=(\mathrm{e}, \mathrm{h})$ " describe una relación de inducción para obtener la prueba de la racionalidad del procedimiento. En particular, el acto con el que se identifican los elementos que constituyen la evidencia no tienen nada de intuitivo y constituye un ejemplo típico de conocimiento empírico en el que tiene lugar el contacto entre los elementos externos y las facultades gnoseológicas del sujeto cognoscente: tal encuentro se puede asimilar correctamente a la percepción del objeto particular, más que a una intuición indeterminada, si solo se tiene en cuenta la elemental distinción que, incluso al nivel del sentido común, se efectúa entre experiencia directa e intuición y que habitualmente se usa precisamente como criterio diferenciador para juzgar la racionalidad de un conocimiento determinado. Consideraciones del mismo tipo se adaptan con facilidad también al acto con el cual se formula la hipótesis, en la medida en que consiste simplemente en la elaboración lógica de los datos ofrecidos por la experiencia empírica: la adherencia de «h» a esos datos es de esa forma el criterio para la valoración de la validez de la hipótesis misma, en el sentido en que su admisibilidad se mide sobre los mismos elementos que se usaron para elaborarla. También en este caso los instrumentos son únicamente los del análisis lógico y la semántica.

Como ya se ha subrayado, tampoco la valoración del grado de confirmación de "h»" en relación con «e» se funda en algo diferente al análisis de las proposiciones en las que se expresan los datos de la experiencia y de aquellas en las que se formula la hipótesis, así como de las relaciones lógicas que se establecen entre ellas. Dado que tanto los actos individuales que componen el procedimiento, como las relaciones que los vinculan, se plantean exclusivamente en el nivel de la elaboración lógica, y que justamente en esta exigencia encuentran su garantía de validez con exclusión de cualquier interferencia de elementos heterogéneos con respecto a ella, de allí se sigue la aplicabilidad inmediata de la noción de racionalidad al modelo aquí considerado. En ese sentido, se puede por lo tanto calificar también al razonamiento judicial como un ejemplo particular de inferencia deductiva de carácter probabilístico.

En lo que tiene que ver con la noción de objetividad, conviene una vez más considerar el razonamiento del juez como caso especial del proceso lógico inductivo, y efectuar sobre él las observaciones necesarias. En el ámbito de los procedimientos racionales de juicio, el criterio más común con base en el cual se distinguen los que pueden calificarse como objetivos, es la ausencia de juicios de valor entre los momentos lógicamente necesarios: su presencia significaría, en efecto, la introducción de un elemento subjetivo, aunque en muchos casos racional, suficiente para excluir la validez objetiva de todo el procedimiento. Un juicio de naturaleza axiológica es esencialmente no controlable, en el sentido en que su repetición implicaría necesariamente una elección del valor con base en el cual se efectúa ese juicio, que es en todo caso arbitraria o que, de todas formas, está por fuera del procedimiento lógico en cuestión: el juicio de valor puede en muchos casos estar justificado, pero no por ello deja de ser irreductiblemente subjetivo. Dada la noción de racionalidad que se ha usado antes, me parece suficiente, para mostrar la 
objetividad del procedimiento examinado, excluir que en su modelo haya elementos valorativos. No es ese, evidentemente, el acto en que se adquiere el dato empírico, justamente porque éste se adquiere (es decir, genéricamente, se percibe) y no es objeto de valoración, sino de un examen que se traduce en el análisis del significado y de la estructura lógica de la proposición con la que se formula. Por motivos análogos, no se puede decir que la formulación de «h» tenga fundamento axiológico, en cuanto es el resultado de una indagación llevada a cabo en un nivel de comparación crítica entre el valor de verdad de las proposiciones relativas a los datos empíricos, y las posibilidades hipotéticas que se concilian con ellas. También la determinación del grado de confirmación de «h» sobre «e», aunque se diga que indica la valoración de la admisibilidad de la hipótesis, es rigurosamente objetiva, tato porque es esencialmente relativa a la evidencia empírica y está estrictamente condicionada por ella, como porque, como ha aclarado Carnap, resulta de un mero cálculo lógico efectuado sobre los resultados de un análisis semántico de las proposiciones contenidas en «e» y en «h». Aunque el grado de confirmación de la hipótesis (es decir, el valor de probabilidad lógica de la afirmación contenida en ella) no sea traducible inmediatamente en términos numéricos, es suficiente la demostración de su carácter cuantificable, sobre la base de un criterio unívoco y constante que garantice su objetividad.

El cálculo lógico que tiene como resultado el valor de probabilidad lógica, en cuanto se define como formal, es abstractamente verificable, no en el sentido en que las afirmaciones a las que conduce se puedan demostrar como verdaderas mediante la comparación directa con la realidad (dado que el método de verificación empírica sólo es aplicable en el ámbito de la ciencia), sino en el sentido en que, conociendo las proposiciones relativas a los datos empíricos sobre los que se fundan y aquellas en las que se expresan la hipótesis, siempre es posible establecer si las relaciones formales identificadas entre tales proposiciones permiten atribuir a «h» ese cierto grado de confirmación lógica. Como sucede para el cálculo originario, también su verificación se desarrolla siguiendo el objetivo binario constituido por el análisis lógico semántico de las proposiciones constitutivas «e» $\mathrm{y}$ «h», sin descender a revisar la correspondencia del primer grupo de proposiciones con el conjunto de los datos empíricos utilizables, sino únicamente controlando si aquél dato «e» está en capacidad de confirmar «h» en la proporción establecida por el cálculo originario. En cuanto se verifica el cálculo como tal y no la verdad empírica de las proposiciones sobre las que se lleva a cabo, y en cuanto las «valoraciones» que se tienen en cuenta en el proceso no son más que momentos particulares de ese cálculo, se puede concluir que la verificación es meramente formal, es decir, en términos jurídicos, que el control sobre el juicio de hecho no hace parte del mérito del juicio mismo y se limita a revisar el carácter lógico del procedimiento con el que el juez formula la hipótesis sobre el hecho y determina su propio convencimiento sobre ella. El valor de probabilidad lógica que de este modo se atribuye a la representación llevada a cabo por el juez, representa la medida de su convencimiento racional sobre el hecho y, como se ha visto, tal medida está determinada objetivamente $\mathrm{y}$ es formalmente verificable. 
Dado que también la elección entre las eventuales y diferentes «h» sigue un criterio objetivo, en el sentido de que se deriva de la comparación entre los diferentes valores de confirmación que se atribuyen a las «h" posibles sobre la base de «e», y no está confiada a la arbitraria valoración del juez (lo cual constituye garantía de racionalidad de la elección), se puede decir que también a ella se le extiende la posibilidad de un control formal, mediante el cual se verifica, sin entrar tampoco en el mérito de la cuestión, si la hipótesis que el juez ha decidido considerar como más admisible (esto es, verdadera con respecto a los datos de confirmación) es realmente aquella a la que «e» permite atribuir el valor más alto de probabilidad lógica.

Para poder decir que la Corte de Casación, al efectuar el control ex art. 360, num. 5, conoce el mérito de la cuestión de hecho, sería necesario sostener que ese órgano no puede llevar a cabo el procedimiento de verificación antes descrito, sin remontarse al conocimiento directo de los datos empíricos de los que el juez de mérito ha extraído las razones de su convencimiento, es decir, es necesario, para establecer la validez del cálculo lógico, repetir la experiencia empírica mediante la cual se lleva a cabo la formulación de los datos empíricos en las proposiciones que constituyen «e». Dado que, por el contrario, el control asume como presupuesto de partida tales proposiciones, sin remontarse a los hechos que ellas expresan, y de este modo toma en consideración únicamente los aspectos lógicos y semánticos, y no el valor concreto y particular de conocimiento (y, por tanto, no avanza en el examen de sus características formales), no se puede decir que tal revisión se resuelva en el reexamen del mérito del juicio de hecho. No son objeto del análisis de la Corte los datos empíricos que el juez de mérito ha adquirido, sino las proposiciones que ha formulado al respecto, y las consecuencias lógicas que ha deducido de ellas: esto me parece suficiente para demostrar la posibilidad del control meramente lógico sobre el razonamiento judicial.

Aunque siga en lo esencial el esquema conceptual antes expuesto, con respecto a la estructura lógica de carácter inductivo del razonamiento judicial sobre el hecho, Piras $^{30}$ llega a conclusiones opuestas, en lo que tiene que ver con la posibilidad del control meramente lógico del juicio de hecho. En otras palabras, él aplica el concepto de probabilidad lógica elaborado por Carnap con el objetivo de identificar el esquema objetivo de ese juicio, como una relación entre hipótesis y evidencia utilizable, con la consecuencia, que se desprende de lo dicho antes, de que la decisión ya no puede considerarse ni cierta ni absoluta; con todo, de ello deduce que, si se supone un control meramente lógico sobre el hecho, la decisión del juez de mérito sobre la suficiencia de la motivación para justificar el convencimiento, sería imposible de controlar. Tal conclusión está motivada porque, en su opinión, no es posible considerar como un control lógico la revisión de la sentencia que se fundamente en una nueva evaluación de los valores de probabilidad de las afirmaciones de hecho, sobre la base de una experiencia más amplia o diferente de la que ya hizo el juez de mérito. La argumentación es correcta, en el sentido en que, cambiando de alguna manera la evidencia relevante,

30. Cr. Piras A., «Le massime d'esperienza e la motivazione insuficiente», en Jus 1955, pp. 89 y ss. 
la verificación de los valores de probabilidad no sería ya un control lógico, sino una revisión del mérito; pero es equivocada, en cuanto no tiene en cuenta el hecho de que la Corte de Casación controla el razonamiento del juez de mérito sobre la base de los mismos datos empíricos que éste ha utilizado al formular el juicio. Si se toma en adecuada consideración este factor, me parece que la tesis que niega la posibilidad del control lógico ya no es sostenible, y se puede reconocer a la Corte el poder de revisar la adecuación de la motivación que justifica la decisión de fondo.

Pienso entonces que es legítimo concluir afirmando que, por consistir el juicio de hecho en la determinación de los valores de probabilidad inductiva de la hipótesis sobre la base de la evidencia empírica utilizable, y por resultar tales valores de la relación lógica entre dos grupos de proposiciones, es perfectamente admisible un control formal sobre la congruencia recíproca de tales proposiciones, expresada de manera objetiva por el grado de confirmación de «h». Me parece que queda confirmada, además, al menos en líneas generales, la validez metodológica del paralelo entre el juez y el historiador, que se había planteado al inicio como hipótesis de trabajo.

\section{BIBLIOGRAFÍA}

Abbagnano, N., 1927, Il nuovo idealismo inglese ed americano, Nápoles.

Bradley, F.H., en Appearance and Reality, Londres.

Braithwaite R.B. 1946-7, «Teleological Explanation», en Proceedings of the Aristotelian Society.

Braithwaite R.B. 1953, Scientific Explanation, Cambridge.

Brodbeck M., 1962, «Explanation, Prediction and Imperfect Knowledge», en Scientific Explanation, Space and Time, H. Feigl y G. Maxwell eds., Minnesota Studies in the Philosophy of Science, vol. III Minneapolis.

Bronowski J., 1951, The Common Sense in Science, Londres.

Calamandrei, P. 1930, «La genesi lógica della sentenza civile», en Studi sul processo civile, vol. I., Padua.

Calamandrei, P., 1947, «Il giudice e lo storico», Studi sul processo civile, vol. V, Padua.

Calamandrei, P. 1955, «Verdad y verosimilitud en el proceso civil», en Rivista di diritto processuale, I.

Calamandrei, P. 1957, Studi sul processo civile, vol. VI, Padua.

Calogero, G. 1937, La logica del giudice e il suo controllo in Cassazione, Padua.

Carnap, R. 1950, Logical Foundations of Probaility, Londres, Chicago.

Carneluttr F. 1925, "Limiti del rilievo dell'error in iudicando in Corte di Cassazione», en Studi di diritto processuale, vol. I, Padua,.

Cohen M., 1929, «The Place of Logic in the Law», 29 Harvard Law Rev.

Cohen M. y Nagel E., 1934, An Introduction to Logic and Scientific Method, Nueva York, Collingwood R.G., 1946, The Idea of History, Oxford

Cornfortg K., 1935, «Explanation in History», en Proc. of the Arist. Soc., Suppl. Vol. 1935.

Crawford R.M., 1947, «History as a Science», en Historical Studies, Australia y Nueva Zelanda. Croce, B., 1926, Riduzione della filosofia del diritto alla filosofia dell'economia, Nápoles, 1926. Croce B.,1938 La storia come pensiero e come azione, Bari. 
Donagan, A., 1959, "Explanation in History», reimpreso en Theories of History, Gardiner, ed. DraY W., 1954, "Explanatory Narrative in History», en The Philosophical Quarterly.

Dray, W., 1957, Laws and Explanation in History, Oxford.

Dray, W., 1958, «Historical Understanding as Re-thinking», en Univ. of Toronto Quarterly, XXVII, n. 2.

Dray, W. 1964, Philosophy of History, Englewood Cliffs.

Ducasse C.J., 1949, «Explanation Mechanism and Teleology» en Read. in Phil. Analysis, Feigl y Sellars eds., Nueva York

Frank, J. 1932, «What Courts do in Fact», Illinois Law Review, 26.

Frank J 1947, "Words and Music», Columbia Law Rev. 47.

Frank J. 1948, «Say it with Music», Harvard Law Rev., 61.

Frank J. 1949, Law and the Modern Mind, Nueva York.

Gardiner, P., 1952, The Nature of Historical Explanation, Oxford.

Goodman N., 1945-8, «On Infirmities of Confirmation Theory», en Phil. Phen. Res., 8.

Helmer O. y Oppenheim P., 1945, «A Syntactical Definition of Probability and of Degree of Confirmation», en Journal of Symbolic Logic, 10.

Hempel, C.G., 1943, «A Purely Syntactical Definition of Confirmation», en Journ. of Symb. Log., 8.

Hempel, C, G., 1945, «Studies in the Logic of Confirmation», en Mind, 54.

Hempel C.G., 1949, "The Function of General Laws in History», en Readings in Philosophical Analysis, H. Feigl y W. Sellars, eds., Nueva York.

Hempel, C.G. 1960, «Philosophy of Natural Science», Prentice Hall Foundation of Philosophy Series, Englewood Cliffs.

Hempel, C.G., 1963, "Reasons and Covering Laws in Historical Explanation», en Philosophy and History, S. Hook ed., Nueva York.

Hempel, C.G. y Oppenheim, F., 1945, «A Definition of 'Degree of Confirmation'», en Phil. of $S$.

Hospers J., 1963, «On Explanation», en Journal of Philosophy of Science, Englewood Cliffs.

Hutcheson N., 1929, "The Judgement Intuitive: The Function of the Hunch in Judicial Decisions», 14 Cornell Law Quart.

Jefrereys H., 1936, Scientific inference, Cambridge; «The Problem of Inference», en Mind 45.

JefFreys, H.,1939, Theory of Probability, Oxford.

Kaufmann, F., 1944, The Metodology of the Social Science, Nueva York.

Keynes J.M.,1921, A Treatise on Probability, Londres y Nueva York.

Lenz J.W., 1956, "Carnap on Defining 'Degree of Confirmation'» en Philosophy of Science.

Mandelbaum, M., 1938, The Problem of Historical Knowldege, Nueva York.

Mandelbaum, M., 1942, "Causal Analysis in History», en Journal of the History of Ideas.

Nagel, E. 1939, "Principles of the Theory of Probability», en International Encyclopaedia of Unified Science, Chicago, vol. I, n. 6.

OAkeshott, N., 1952, Experience and its Modes, Cambridge.

Paul, J. 1959, The Legal Realism of Jerome N. Frank, La Haya.

Piras, A., 1955, "Le massime d'esperienza e la motivazione insufficiente», en Jus.

Popper, K., 1935, Logik der Forschung, Viena.

Popper, K 1945, The Open Society and its Enemies, Londres.

Redenti, E., 1938, Profili pratici del processo civile, Milán. 
Rescher, N. y Helmer, O., 1959, «On the Epistemology of the Inexact Sciences», en Management Science, VI, n. 1.

Rescher, N. y Joynt, C.B., 1959, «On Explanation in History», en Mind, LXVIII, 271.

Rocco, A., 1906, La sentenza civile, Torino, 1906.

Rosi, P., 1954, «Teoria della storia e della metodologia storiografica nel pensiero inglese contemporaneo", en Riv. Storica italiana.

Rudner, R., 1960, «Philosophy of Social Sciences», Prentice Hall Foundation of Philosophy Series, Englewood Cliffs.

Scriven, M., 1959, "Truism as the Ground for Historical Explanations», en Theories of History, Gardiner ed.

SCriven, M., 1963, «New Issues in the Logic of Explanation», en Philosophy and History, Hook ed., Nueva York.

Scriven, M., 1963, «The Historical Explanation of Actions Reconsidered», en Philosophy and History, Hook ed.

Stein, F. 1983, Das Private Wissen des Richters, Leipzig.

Strong, E.W., 1952, "Criteria of Explanation in History", en Journal of Philosophy.

Swabey, M.C., 1954, The Judgement in History, Nueva York.

Teggart, F.G., 1941, Theory and Process of History, Berkeley y Los Angeles.

Teggart, F.G., 1942, "Causation in Historical Events», en Journal of the History of Ideas.

Trevelyan, G.M., 1930, Clio, A Muse, Londres.

Walsh, W.H., 1951, An Introduction to Philosophy of History, Londres.

WeHLI, A.:1913, "Beiträge zur Analyse der Urteilsfindung», en Festschrift für A. Wach, Leipzig.

White, M., 1939, «Probability and Confirmation», en Journal of Philosophy, 36.

White, M.G., 1943, «Historical Explanation», en Mind. 